\title{
Supporting Teacher Reflection through Online Discussion
}

\author{
Jiening Ruan* \\ Jeannine Rainbolt College of Education \\ University of Oklahoma, USA \\ E-mail: jruan@ou.edu

\section{Priscilla L. Griffith} \\ Jeannine Rainbolt College of Education \\ University of Oklahoma, USA \\ E-mail: pgriffith@ou.edu \\ *Corresponding author
}

\begin{abstract}
The purpose of this case study was to investigate online discussion as a means to promote critical reflection. The study was conducted during a semester-long graduate course on issues related to literacy instructional strategies. The participants in the study were four reading education candidates. During the semester they participated in online discussion about course readings and reflected on their own teaching experiences. The data sources were the online discussion postings, responses to questionnaires, and interviews. The results suggest that technology-mediated discussion strengthens the learning community, facilitates sharing of professional experience among participants, and enhances teacher reflection. The results also point to the multi-faceted nature of teacher reflection.
\end{abstract}

Keywords: Technology-Mediated Discussion; Online Discussion; Teacher Reflection

Biographical notes: Dr. Jiening Ruan is an associate professor of literacy and reading education and chair of the Reading Specialist Certification Program at the University of Oklahoma. Her research interests include literacy development of diverse student populations in the United States and in international contexts, teacher reflection, and technology and literacy integration.

Dr. Priscilla L. Griffith is a professor and the Ruth G. Hardman Chair in Education at the University of Oklahoma where she directs the Hardman Center for Children with Learning Differences and the Oklahoma Writing Project. Her research interests include early literacy learning and teacher professional development.

\section{Review of the Literature}

Reflection is a term that has been used by different people to mean different things. According to Dewey (1938), reflection is an "active, persistent, and careful consideration of any belief or supposed form of knowledge in the light of the grounds that support it 
and the further conclusions toward which it tends" (p. 9). Dewey considered reflection an essential and highest form of inquiry. Building upon Dewey's conception of reflection, Schon $(1983,1996)$ proposed the term reflective practice and posited that it involves thoughtful consideration of one's own experiences while trying to connect theory to practice.

Reflection is an experience-based process for exploring issues of concern and can lead to changes in understandings, conceptual perspectives, and future actions (Boud, Keogh, \& Walker 1985; Boyd \& Fales, 1983). It is also an inquiry-based practice that supports professionals in developing problem solving abilities surrounding "making sense of uncertainty, performing artistically, setting problems, and choosing among competing professional paradigms" (Schon, 1983, p. 20). Various traditions exist concerning reflection (Zeichner \& Liston, 1996). Common to each of these discussions of reflection is that a reflective practitioner understands the limitation of professional knowledge gained through recurring experiences and seeks to gain newer understandings of the profession and its related practices.

Supporting reflection is a widely accepted and desired practice in teacher education programs (Dieker \& Monda-Amaya, 1995; Ferraro, 2000). Reflection on teaching experiences can improve teachers' learning process and decision-making (Richardson, 1990), strengthen teacher self-efficacy and identity (Urzua \& Vasquez, 2008), and produce "more skilled, more capable, and in general better teachers" (Zeichner \& Liston, 1996, p. xvii). Research on teacher effectiveness suggests that a strong link exists between critical reflection and effective teaching (Harris, 1998). When teachers engage themselves in critical reflection and reflective practice their own teaching reaches a higher level in at least three ways. They examine and challenge their existing understanding of teaching and learning. Their own teaching practices become more mindful of the connection between theory and practice. Finally, they achieve greater coherence between their personal theory of teaching and learning and their own teaching practices.

The socioconstructivist viewpoint (e.g., Bruner, 1996; Vygotsky, 1978) claims that learning is a social process. Individuals actively construct knowledge in a social environment by interacting with people around them, especially those more knowledgeable others. In essence, human learning is culture-based and deeply situated in sociocultural contexts consisting of socioculturally specific understandings, practices, and traditions. In many professional fields, developing "communities of practice" has become an increasingly popular concept for promoting knowledge, learning, and change among professionals with "shared expertise and passion" (Wenger \& Snyder, 2000, p. 139). Similarly, the importance of establishing a learning community to facilitate reflective thinking among teachers is also well recognized in teacher education literature (e.g., Putnam \& Borko, 2000; Zeichner \& Liston, 1996). It is essential to build an environment that promotes dialogue and conversation among participants with different perspectives (Zeichner \& Liston, 1996). Diverse perspectives and experiential backgrounds can expand the scope and depth of reflection. In turn, collective reflection also strengthens the learning community (Bullough \& Gitlin, 1995).

Unfortunately in practice in many teacher education courses, reflection is still primarily treated as a private and personal act rather than a communicative and discursive act. A comprehensive literature review conducted by Roskos, Vukelich, and Risko (2001) reveals that general strategies used to promote reflective thinking in teacher education courses are personal journals, case studies, portfolios, and autobiographies. These traditional strategies are not in line with our current understanding about the nature of 
learning and professional growth although they are still in wide practice in teacher education across the nation.

The latest advancement in technology provides unprecedented opportunities for teacher educators to support reflection as a collective and dialogic practice. The Internet extends space for interaction. In an online forum, teacher candidates do not have to rely on face-to-face contact to communicate and/or interact with each other to support each other's thinking and learning. A computer-mediated learning environment affords convenience and flexibility for members of a learning group to engage in frequent dialog and conversation online (Mark, Thadani, Calonge, Pun, \& Chiu, 2011; Wood \& Smith, 2001). In addition, unlike in oral communication settings, online discussion is text-based, therefore allowing teachers more time to process thoughts and ideas of self and others (Lowry, Koneman, Osman-Jouchoux, \& Wilson, 1994). As a result, more in-depth and thoughtful reflection could occur. If organized well, online discussion can effectively elicit rich reflection on specific as well as broad issues related to teaching and learning (Harrington \& Quinn-Leering, 1996).

However, several drawbacks have been noted in previous research on how online communication in a form similar to most listserves might influence teacher reflection. Among them, the unstructured nature of online discussion groups is a factor that frequently leads to superficial comments and descriptions instead of truly reflective inquiry (Edens, 2000). In addition, the lack of organization and facilitation in the online environment often results in uneven participation among the participants (Ruan \& Beach, 2005; Edens, 2002).

In general, in light of our knowledge of teacher reflection, interactive learning, and technology integration, online discussion groups have great potential to become a powerful instructional strategy that promotes teacher reflection and inquiry. Yet existing literature also points to pitfalls and to our limited understanding of technology-facilitated discussion, a recently added but not well-understood dimension of teacher education (Edens, 2000; Fetterman, 1998; Windschitl, 1998). There is a critical need to develop strategies that promote dialogic processes and reflection in technology-mediated, community learning contexts (Edens, 2000; Ruan \& Beach, 2005).

In this case study, the participants were enrolled in a graduate reading education methods course. This course was one of the core courses in the reading program and was designed for the program candidates to examine the best practices for supporting learners' development as strategic, engaged readers from the early years through adolescence. The class met once every week for three hours to explore key issues discussed in the readings and provide opportunities for face-to-face interactions, discussions, and other learning activities.

Since we consider out-of-class learning as essential to the candidates' growth, we sought to extend the physical learning space through the use of a virtual learning community where the candidates could engage in social interactions to share their experiences and meet their learning needs without the constraints of time and physical location. Online technologies available at the university made it possible for the candidates to engage in further social interactions in the virtual environment. In order to take full advantage of a technology-mediated learning environment and avoid the pitfalls identified in the existing literature on online discussion, we developed a new approach to conducting online discussion that provided more ownership and structure. The questions that guided this study were: a) How did the new approach support teacher reflection? b) What types of reflection existed in the participants' online discussion? 


\section{Method}

\subsection{Participants}

This was a qualitative case study conducted during a semester-long graduate level course on issues related to literacy instructional strategies. It was a small size class with only four female students, and all of them volunteered to participate in the study (pseudonyms: Jane, Megan, Mona, and Tara).

The participants came from various backgrounds with different cultural frames. The common denominator was that they all had public school teaching experiences and had returned to the graduate reading education program for further study. Every participant had taught in elementary schools before they took this course. Their teaching experience ranged from three to six years. Three of the participants were elementary school teachers at the time of the study, and the fourth was a graduate research assistant for a faculty member in the department.

Three members were European Americans, and one was African American. Mona was teaching fifth grade at a rural middle school. Megan, who used to be a teacher at an urban public school, was taking care of her new-born baby while attending the graduate school and working as a graduate research assistant. Jane was teaching second grade in a Title I school (with most children coming from homes of low social economic status) in the town where the university was located. Tara, the African American student, was teaching first grade in a predominately African American urban public school.

\subsection{Procedures}

In this course, students were required to engage in collective reflection. They participated in weekly online discussion about course readings. The assignment was to encourage the candidates to critically reflect on the content of the readings and make connections to their own teaching practices. In the study, the participants were required to lead online discussions, and they selected topics that were of interest to them from a list of topics given to the entire group by the lead researcher. The researchers took into consideration the drawbacks of the online discussion strategies reported in earlier studies and made several modifications. First, to ensure that all participants understood how to use the online forum before the study began, the lead researcher, also the course instructor, modeled the use of the Message Board (the Internet forum used at the researchers' University) for online discussion. The participants were provided opportunities for guided practice in class until they indicated that they felt comfortable with communicating on Message Board. Second, to eliminate possible problems associated with the unstructured nature of the previously documented online discussion procedures (e.g., Ruan \& Beach, 2005; Edens, 2000), the participants were asked to take turns serving as the weekly discussion leader. They brainstormed ideas on how to have a successful and productive online reflection experience and came to the agreement that a leader's main responsibility was to organize and lead the weekly online discussion by prompting and facilitating her peers to reflect on the course readings and their own teaching experiences in relation to the topic of the week. The leader also had the responsibility of keeping the dialogue going by clarifying ideas, raising further questions, challenging other's thoughts, and bringing the discussion to a productive conclusion at the end of the week. They agreed that each group member should be supportive of the weekly group discussion leader by responding to her questions and postings in a timely 
and thoughtful manner. Finally they proposed that as much as possible, they should respond to each other's reflections.

Each leader communicated with the rest of the class about her expectations for how the discussions should be conducted during the week she was in charge. As a group, the participants took the initiative and came up with a system for online discussion that allowed for both structure and flexibility. Because the class meetings were on Mondays, they decided that on Wednesday the week before, the discussion leader would post her questions related to the week's readings for the class to respond to and reflect upon. The group members could post their responses to the leader's questions and to each other's discussion messages anytime before Sunday, and a member could also post multiple responses, if so desired. On Sunday, the leader would conclude the discussion by summing up the discussion and clarifying issues of tension or concern. They also decided that if the leader of the week had any special requirements, she could inform the rest of the group in her message to the group. All these online discussions became a springboard for the coming Monday night's class meeting.

Throughout this process, the lead researcher assumed the role of facilitator and did not participate in the discussion. To address the power issue, the students were informed that they owned this activity, meaning they could do it anyway they decided would facilitate the discussion. They also would get full credit so long as they participated actively in the assignment and fulfilled the group's expectations. Their online discussion would not be subject to any other grading criteria. This was out of the consideration for providing a student-centered forum where the participants could talk about any issues of personal interest and concern related to the weekly readings without the fear of being evaluated. However, they were also informed that the instructor (lead researcher) would read their discussions in order to inform her class instruction. Due to the exploratory nature of this activity, no other restrictions were put forth.

\subsection{Data Collection and Analysis}

In addition to posting weekly discussion questions and responses, the participants were asked to fill in two electronic questionnaires, one before and one after the experience. The questionnaires had both close- and open-ended questions to allow the participants to make further comments on the value of using this online discussion model to support their reflection and learning. The lead researcher also conducted interviews regarding the project with individual participants.

Content analysis (Patton, 1990) was used as the major method of data analysis in this study. Open coding was conducted to identify initial concepts in the data. The researchers read and reread all discussion messages, questionnaire responses, and personal interview transcripts line by line to identify possible concepts. Specific codes were identified to describe those concepts. For example, in many discussion messages, the researchers found that the participants often confirmed and affirmed each other's viewpoints, and therefore confirmation and affirmation became two initial codes that were used to reflect those two concepts. The process of open coding was applied to all the data. Each code was tested against the incoming data until the point of saturation was reached and no new concept could be identified.

The next step was to group conceptually similar codes into larger categories. In this case, the category of providing support and showing solidarity toward each other was identified to capture the codes of confirmation and affirmation. Afterwards, axial coding was applied to identify relationships among the categories to form themes (Strauss \& 
Corbin, 1998). The two research questions were also used to inform this particular step of analysis so that the final themes kept and reported in this paper were related to the two research questions set for the study. Representative data clips, from which the themes were derived, were selected to illustrate the themes and assertions.

Researcher triangulation was used in order to ensure accuracy and credibility of data analysis and interpretation. The two researchers coded data separately and constantly discussed issues related to data analyses. They resolved the discrepancies through discussion.

\section{Findings}

This section contains a description of the major themes and subthemes that emerged through the iterative data analysis process. Two major themes were identified: the value of online discussion and the multi-faceted nature of teacher reflection in the context of online discussion.

\subsection{Value of Online Discussion}

Data analysis led to six subthemes related to the value of online discussion: community building, confidence building, convenience, flexibility, opportunity for reflection and response, and peer input to expand thinking. These subthemes are discussed below.

\subsubsection{Community Building}

The data indicate that online discussion contributed to community building within the class. The participants constantly engaged themselves in the act of providing emotional support and showing solidarity toward each other. A positive, supportive online environment was established and cultivated by all members of the discussion group.

The participants encouraged and cheered for each other especially for the weekly leader. Comments such as "Jane, Great questions!...Once again, great questions!" and "I really like your questions" were regularly made by all participants. The leaders also frequently expressed appreciation for the active participation from their peers. For example, in her response to the group, Jane wrote, "Great responses! I want to say thank you to everyone. I thought that the responses were insightful and thoughtful" (Jane, Online Posting, 03/25). They also regularly affirmed each other's viewpoints.

I just read your posting in reference to questions one and two. After reading it, I had to respond. I absolutely agree with you about what you said in reference to the authors [sic] opinion... I also agree with you on your statement concerning the placement of these students. I think it is important that students spend time both in a resource room and in the regular classroom. (Mona, Online Posting, 03/02).

In response to Tara's posting on the challenge of getting some of the parents involved in their children's reading education and the things she did to try to address that, Megan wrote, "I had a similar challenge when I was teaching. I really like what you did to increase parental involvement. Keep going!” (Megan, Online Posting, 04/08)

The participants appreciated the constant exchange of ideas among the group members afforded by this activity. For example, Megan wrote in her post questionnaire, 
"The online discussion allowed me to voice my opinions and to read what my classmates had to say... This way, you have a chance to read everyone else's ideas" (Megan, Questionnaire, 05/24). Responses such as these indicated that the participants considered themselves part of a learning community where they felt comfortable sharing their ideas and valued each other's thoughts and opinions.

Interview data also support this subtheme. Mona said, "I like online discussion because I feel my peers value my opinions. I also learn so much from them. The struggles they have gone through and the lessons they have learned. I feel we have become better teachers because of each other." (Mona, Interview, 05/03)

\subsubsection{Confidence Building}

Tara recognized the non-threatening feature that online communication afforded, "It also allows the more passive students an opportunity to be more assertive during an online discussion because they are in a less threatening environment and may feel more comfortable about speaking out." (Tara, Questionnaire, 03/02).

Tara also commented,

The most important aspect of the online discussion was that it afforded everyone an opportunity to 'comfortably' share information and ideas. It provided a 'safe' environment where all ideas where heard and accepted...If I am expressing my ideas or responding via the Internet, I do not have to concern myself with other's body language, attention span, or any other aspects that might cause me not to express myself freely and honestly. (Tara, Questionnaire, 05/26)

\subsubsection{Convenience}

One major attraction of computer mediated online discussion identified by the participants was convenience. Online discussion eliminates the difficulties caused by the lack of time and physical location needed for communication outside of the class. "I think online response is great because it facilitates discussion between classmates that we may not have time for in the regular classroom setting" (Megan, Questionnaire, 02/27). Similarly, Mona noted, "I know personally with my busy schedule getting online and posting any questions I have is a lot easier than trying to get a hold of someone by telephone" (Mona, Questionnaire, 02/25). Jane also indicated the fact that online discussion provided "the freedom of when and how to do it" (Jane, Questionnaire, 06/13). Related to convenience is the notion that the use of online discussion extended the learning space from traditional classrooms to cyber space. "The value of this strategy is that classmates have a way of communicating to each other throughout the week. Discussion doesn't have to wait for the next class session.” (Jane, Questionnaire, 06/13)

\subsubsection{Flexibility}

The flexible, informal format of online discussion provides attraction. The asynchronous nature of online communication allows the participants to contribute at a convenient pace and time, and in bits and pieces. In one of her weekly discussion messages, Megan wrote, "Hi everyone....I've had a crazy week...so I'll respond in bits and pieces.....and contribute to what you all respond. See you Monday" (Megan, Online Posting, 03/02). 


\subsubsection{Opportunity for Thoughtful Reflection and Response}

One other welcomed advantage was the time to reflect before giving a response. In contrast to face-to-face dialogue, with online discussions, the receiver is removed in space from the sender. This allows the receiver/responder time to think about what needs to be said before responding. According to Jane, “...I think that reflective thinking has a chance to expand" (Jane, Questionnaire, 02/27). On the follow-up questionnaire, Jane further noted,

I have learned to be more reflective in what I write. This is due to the fact that other classmates will read what I have to say. I need to know what I think and how I want to express myself in a way that communicates effectively to others. When talking face to face or writing a personal journal, how you express yourself is different. In a face to face discussion, body language and tone of voice have an influence. In a personal journal, there is only one audience member, usually, yourself. (Jane, Questionnaire, 06/13)

The participants clearly indicated that the online discussion contributed to their thinking critically and reflectively. Tara commented on how her sense of audience contributed to her being more reflective when doing online discussion.

When I type out my thoughts on various readings, I discuss information that is important to me or relevant to my situation. I probably only concern myself with how the information effects [sic] me, and not how it might apply to my colleagues or its effectiveness outside the classroom. With online discussions, I am required to think beyond my own personal attitudes/concerns because what I might find important may not be of concern to someone else. Online discussions help me think beyond firstgrade students or beyond how information might apply to my daughter. (Tara, Questionnaire, 05/26)

\subsubsection{Peer Input to Expand Thinking}

The participants also found that they benefited from other's unique inputs and perspectives. Ideas from other discussion participants could stimulate and expand their thinking.

One of the values of this strategy is that it increases the rate of feedback you receive from your comments. I also found that reading someone elses [sic] ideas helped me to decide what I should write about. On occasion I found that these discussions helped me to notice things about a chapter, etc. that I hadn't noticed on my own (Mona, Questionnaire, 05/23).

The participants developed a deepened appreciation for online technology at the completion of the project. The data suggest that they enjoyed computer-mediated communication in the online forum, and they all indicated that online discussion facilitated reflection.

\subsection{Multi-Faceted Nature of Teacher Reflection}

The findings indicate that the participants were actively engaged in reflective thinking and learning through connecting theory to personal, classroom experiences. Although the reflective questions asked by the discussion leaders were experience-based, their 
questions were embedded in the theories and the research findings they had just encountered in the weekly course readings and class discussions.

In their online discussion, bolstered by the support from their peers, the participants were able to build their own understanding of what effective instructional practices should be like. They viewed expert knowledge (book knowledge) through a critical lens, using their own teaching experiences, knowledge of school context, and student factors to inform their intellectual decisions. They demonstrated a wide range of reactions to expert viewpoints, and they did not accept everything they read. They drew heavily upon their experiences in practice when processing what they had read from the class readings and when presenting their responses. At times they supported expert viewpoints, and at other times they challenged and disputed viewpoints. They offered their own interpretation of the issues and instructional practices/strategies discussed in the course readings. Below we describe major types of reflection demonstrated in the online discussions.

\subsubsection{Making Personal Connections}

The participants showed great interest in instructional strategies and their use. They were able to contextualize the strategies introduced in the course readings and class discussions and demonstrated new understandings by making different kinds of personal connections to those strategies. For example, Jane wrote, "This week's reading brought up a lot of reflection and questioning for me. I stopped and thought about just how I go about teaching vocabulary. (Jane, Online Posting 03/24)

The participants expressed willingness to use the new strategies they had learned from the course readings and implement them in their future teaching. Megan's comments were short but very typical. "Reciprocal Teaching- I may try this a time or two. It is different from what I am used to but I am willing to try it." (Megan, Online Posting, 03/02)

They shared with the group what they did in their own classroom. In particular, they often described their own classroom application of the strategies with which they strongly identified or had used successfully in their teaching. "My units are usually two weeks (ten days)...Usually I incorporate various subjects into each unit, and it takes most of the afternoon" (Tara, Online Posting, 03/03)

In their discussion postings the participants frequently made connections to other similar strategies they had known or used. They sometimes related the new strategies to other strategies that could accomplish similar instructional goals.

For example, I like the idea of having the students keep a journal as they read independently. However, I think I would change that to have the students make a word wall. Everytime [sic] that they wanted to know the definition for they could write it down on a post-it note and hang it on a wall in the classroom. The students could look up the definitions when they got a free chance and then everyone, not just that student, is exposed to a new word. (Mona, Online Posting, 03/22)

The participants constantly contemplated ways to modify the new strategies described in the readings and class discussions to fit their own classroom need. Applicability was an important consideration when they examined the value of a particular strategy. 
When I finished reading this article I began to wonder if it would work in my classroom. I think my students still need pictures in order to maintain their interests and help with decoding. But I am contemplating creating a book-a small one of course-that we could use to try out this idea. Of course the pictures would have to be clip art pictures and most of the words might be Dolch words, but I think it might work. (Tara, Online Posting, 03/03)

All the participants were sensitive to student needs. They often identified studentrelated factors to support or challenge the use of certain strategies.

I think students with disabilities benefit from being included in regular classroom situations because the other students can serve as role models. It is also good for regular students because they can learn to help others. (Tara, Online Posting, 03/02)

They could put strategy use in perspective. They often identified context-related factors to support or challenge the use of certain strategies.

I liked the idea of the embedded reading, but am afraid that it would not be practical in a regular classroom. First of all is the time factor and second of all is the fact that I don't know any administrator, etc. who would ever consent to letting the kids mark in the book. If they couldn't mark in the book I would be afraid that this idea would be like Shurley English [sic]. The experience I had was that Shurley English worked in certain contexts, but not any others. (Mona, Online Posting, 03/03)

\subsubsection{Acquiring New Knowledge}

The participants frequently showed their excitement about their newly acquired knowledge and indicated their intention to implement recently learned strategies in their teaching. This could be noticed in Mona's response.

In reference to question number two I think I would do EXACTLY what Chapter 7 suggests. I would have short 10-15 minute lessons a couple of times a week. This way I could still stick with what my district mandated and yet introduce some new ways at the same time (Mona, Online Posting, 03/22).

\subsubsection{Challenging Expert Ideas}

The participants often questioned and challenged expert viewpoints in light of their own experiences. As shown in Tara's response, they did not hesitate to refute the expert viewpoints with which they did not agree.

As I read on, I began to believe the authors were faulting teachers because 'that instruction' conflicted with other duties. I do not agree with that statement, and had issues with it because it made me feel as though they were saying if a teacher did not want to utilize this type of instruction due to time constraints, etc., then there is something wrong with that teacher...So, if they believe students with high-incidence disabilities should be in a resource room all day, I TOTALLY disagree. I DO, however, believe that resource teachers and general education teachers should work together so the child is learning connected and related information. (Tara, Online Posting, 03/02) 


\subsubsection{Critically Examining Their Own Practices}

The participants also examined their own practices and strategy use in light of the readings that they did. They tended to provide justification for their own instructional practices.

I like the idea of SRE... I already use a variety of activities to activate prior knowledge and we discuss what was read and what we got out of the reading. As to the whole process, I don't use it because I feel a pressure to move onto other content and curriculum needs based on what we need to cover each year. I would like to try an extended reading with my units next year. (Jane, Online Posting, 03/03)

\subsubsection{Grappling with and Resolving Tension Between Good Practice and School Reality}

The participants often described their struggles with the constraints they faced in school. They tried to grapple with the tension between using the good teaching practices described by the experts and the reality of teaching, and they sought ways to resolve the tension. Many discussion questions involved the challenge, dilemma, confusion, or tension that the leader had experienced. In order to answer the questions posed by each discussion leader, the group members had to carefully reexamine their own perceptions, assumptions, and existing teaching practices in light of the theories and research-based instructional strategies. For example, Tara posed the following discussion question:

Scenario: You have read research on the benefits of Word Walls, Big Word Boards, Nifty-Thrifty-Fifty Walls, etc. You would like to incorporate at least one of these activities, however, your district reminds you of the twentypercent rule regarding paper. You already have a Saxon Math board, and a board for your reading program (for practical purposes we will call this program Success for All) each utilizing twenty-percent of the east and west walls. The north wall is windows, and the south wall consists mostly of a VERY large chalkboard. You REALLY want to incorporate at least one of these ideas because you know how much your students will benefit, but cannot see how to do it. What would you do? (Breaking the law is not an option.) (Tara, Online Posting, 02/16)

This question elicited passionate responses from the rest of the group members. Each offered Tara advice of how to deal with the dilemma so that she could do what she felt was the right thing, but at the same time be within the constraints posed by district policy. In a different posting Tara responded to a weekly leader's posted dilemma in which she demonstrated her effort to bridge the gap between a best practice and the reality of the classroom.

In response to the question about Skinny Books I agree that it does sound very interesting. I also agree (with Mona) that it would be difficult to do in a regular classroom. I think the first thing you would need to do is (to) cut down the number of articles included to about 10 . The copy problem is a very serious one. Think about, I have twenty-five students. If each student copied one article that was one page long (yeah right) that would be 250 articles per child and 2500 articles in my class. Remember that's just one page copies. My principal would throw a fit. What if the Skinny Books instead of containing copies of the articles contained like a list of resources. It could be 
divided into different sections. There could be a list of resources for magazine articles, internet sites, books, and community resources. All of these resources would be on a particular subject and would still require the students to do research. (Tara, Online Posting, 04/20)

\section{Discussion}

The findings suggest that the innovative online discussion strategy the authors implemented in this study enhances and facilitates teacher reflection. The participants in the online environment engaged themselves in multi-faceted, multi-leveled reflective thinking, some of which involved higher level critical thinking (e.g., critical examination of one's own practices, questioning expert's ideas, and finding solutions that reconcile the tension between ideal practices and the realities of schooling and education).

Based on the findings of this study, we propose a model for effective online discussion. The model contains several important constructs and is depicted in Figure 1.

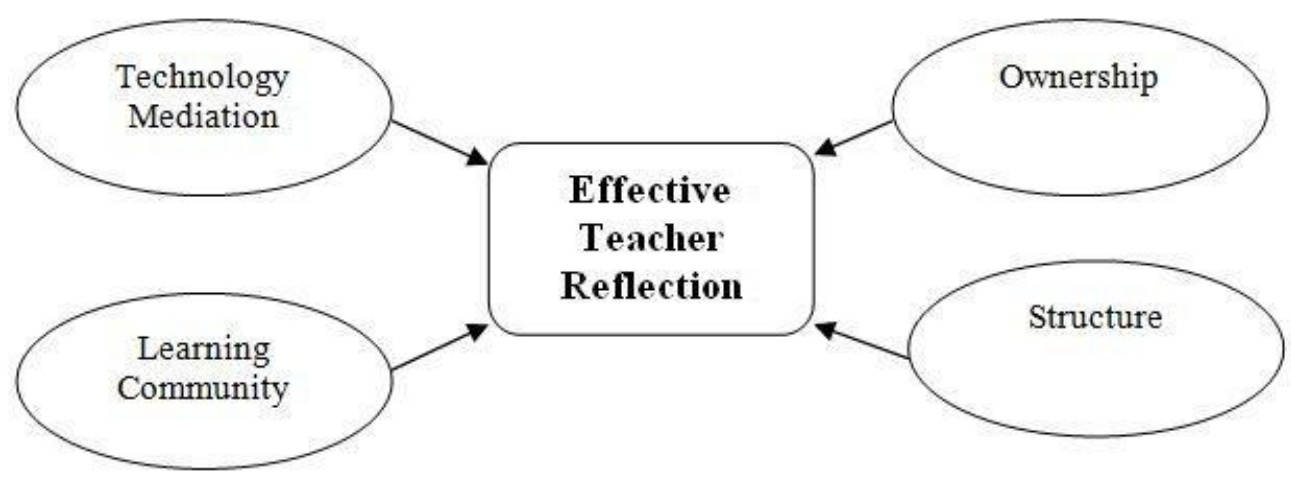

Figure 1. Model of technology-mediated teacher reflection

In this model, effective reflection is supported by four critical components. The first component is learning community, in this case study a community of learners and practitioners. Instead of treating reflection as a personal isolated act, teacher candidates engage in collective reflection that supports and extends each other's thinking and learning. The support from members within the community and the constant idea exchange benefit everyone involved in the discussion and contribute to each member's professional growth.

The second component is ownership. In this model, teacher candidates take charge of choosing their own topics, setting their own rules, and communicating their expectations. This ownership attaches personal significance to the activity leading to stronger motivation and active participation.

The third component is structure. Teacher candidates discuss and set up a structure that ensures participation and holds each one accountable to the success of collective reflection. Having the structure set up by the participants makes the task realistic and accomplishable. 
The fourth component is technology mediation that affords flexibility, convenience, and a non-threatening environment to construct and share thoughts and reflections. Technology extends the learning space and provides opportunities for more expanded and thoughtful reflection. In addition, technology indirectly affects teacher reflection by supporting community building, and community building directly contributes to teacher reflection. Finally, the interactive nature of online discussion requires the participants to carefully consider the needs, responses, and reactions of the community as well as the best way to share their reflection in the online environment. The metacognitive thinking required for successful interaction leads to greater and more meaningful teacher reflection.

The findings from this study emphasize how a supportive social environment mediated by online technology affects teacher knowledge construction and reflection. The results from this study support the view that reflection is as much a social act as it is an individual act (Zeichner \& Liston, 1996). A supportive virtual environment with opportunities for constant and consistent social interaction facilitates reflection. A learning community is valuable to its members in terms of generating new knowledge and reinforcing and renewing themselves (Wenger \& Snyder, 2000). Results from this study indicate in teacher education courses, social interaction is a critical component of teacher reflection.

The results specifically related to the types of reflection in the context of online discussion suggest the importance of teacher experience in reflection. In this study the participants' experiences facilitated their engagement in thoughtful reflection. The connection between experience and reflection triangulated clearly through the data sources. The participants reflected on their teaching experiences, actions, and thinking all together in light of the theories and research-based best practices they were encountering in the course. Equipped with their experiences in teaching, the teachers were able to contextualize instructional theories in the actual classroom. The findings have a guarded application to pre-service teacher education as well. In order for pre-service teachers to reach higher levels of reflection, teacher educators should seek to provide a range and a sufficient amount of field experience to develop practice-based knowledge.

Academic, social efficiency, developmental, and social reconstructionist traditions are four of the teacher reflection traditions identified by Zeichner and Liston (2006). The academic tradition emphasizes reflection on the content and its delivery methods. The social efficiency tradition emphasizes the use of research-based instructional approaches for efficient transmission of knowledge. The developmental tradition highlights the developmental and cultural aspects of student learning. The social reconstructionist tradition focuses on equality, social justice, and democracy in schooling. Even though the participants engaged themselves in various forms and levels of reflection related to the academic, social efficiency, and developmental traditions, the results indicate that critical reflection on social and cultural aspects of teaching and learning (social reconstructionist tradition) was not evident in their postings. Zeichner and Liston (1996) raised the issue about the lack of pre-service teacher reflection on social justice and equality of learning. The participants in this study demonstrated a similar lack of attention to social and cultural influences on learning and teaching. Due to the mature level of reflection demonstrated in these teachers' reflective discussion, the researchers question the extent to which social reconstruction is an aspect of teacher education that has not been adequately addressed in many programs. It is possible that the content/structure of this study precluded the teachers from commenting on this important aspect of reflection. However, this issue has to be more carefully examined in future studies of teacher reflection. 
This study supports the concept of transferring learning responsibility to teacher candidates. In this study, the participants set up their own rules and decided their desired structure of communication. They determined the what, when, and how structure for conducting the online discussion and collective reflection. Because they owned the structure, they were motivated to participate fully in the activity. Ownership of the structure along with a learning community enhanced the teachers' equal participation in the discussion.

This study has some limitations. Although it identified several types of teacher reflection, the categories may mirror the influence of the content of the course, which focused on theories and best practices in reading instruction. The themes and patterns of reflection might differ in a teacher education course with a different instructional focus (e.g., a social reconstruction focus).

A second limitation is the nature of case study, which is always bounded by characteristics that require caution in generalizability, and in this particular case the small number of participants. Readers of this paper should be careful about generalizing the results to courses with a different learner population or with a larger number of education candidates. Still, it is worthwhile to note that the lead researcher was successful in applying the same strategy in another graduate level course with more teacher candidates. In this second application of online discussion students were assigned to several smaller groups of 4-5 members. All other procedures remained similar to those described in this paper. Such a modification led to similar results found in this study.

To conclude, the online discussion strategy investigated in this study is effective in supporting teacher reflection. Teacher candidates were actively engaged in collaborative learning in a supportive virtual community. The participants were able to co-construct meaning about the reality of teaching and learning, critically examine their own practices, and become reflective practitioners through computer-mediated communication in a learner-centered virtual environment.

\section{References}

1. Boud, D., Keogh, R., \& Walker, D. (1985). What is reflection in learning? In D. Boud, R. Keogh \& D. Walker (Eds.), Reflection: Turning experience into learning (pp. 7-17). New York: Nichols Publishing Co.

2. Boyd, E.M., \& Fales, A.W. (1983). Reflective learning: Key to learning from experience. Journal of Humanistic Psychology, 23(2), 99-117.

3. Bruner, J. (1996). The culture of education. Harvard University Press.

4. Bullough, R., \& Gitlin, A. (1995). Becoming a student of teaching. New York: Garland.

5. Dewey, J. (1938). Experience and education. New York: Touchstone.

6. Dieker, L.A., \& Monda-Amaya, L.E. (1995). Reflective teaching: A process for analyzing journals of preservice educators. Teacher Education and Special Education, 18(4), 240-252.

7. Edens, K.M. (2000). Promoting communication, inquiry and reflection in an early practicum experience via an on-line discussion group. Action in Teacher Education, 22(2), 14-23.

8. Ferraro, J.M. (2000). Reflective practice and professional development. Eric Digest. ED449120. 
9. Fetterman, D. (1998). Ethnography. Thousand Oaks, CA: Sage Publications.

10. Harrington, H.L., \& Quinn-Leering, K. (1996). Written case analyses and critical reflection. Teaching and Teacher Education: An International Journal of Research and Studies, 12, 25-37.

11. Harris, A. (1998). Effective teaching: A review of the literature. School Leadership and Management, 18(2), 169-183.

12. Lowry, M., Koneman, P., Osman-Jouchoux, R., \& Wilson, B. (1994). Electronic discussion groups: Using e-mail as an instructional strategy. Tech Trends, 39(2), 22-24.

13. Mark, K-P, Thadani, D.R., Calonge, D.S., Pun, C.F.K., \& Chiu, P.H.P. (2011). From neophyte to experienced facilitator: An interactive blended-learning course for graduate teaching assistants in Hong Kong. Knowledge Management and Elearning: An International Journal, 3(2), 153-169.

14. Patton, M. (1990). Qualitative evaluation and research methods. Newbury Park, CA: Sage Publications.

15. Putnam, R.R., \& Borko, H. (2000). What do new views of knowledge and thinking have to say about research on teacher learning? Educational Researcher, 29, 4-15.

16. Richardson, V. (1990). Significant and worthwhile change in teaching practice. Educational Researcher, 19(7), 10-18.

17. Roskos, K., Vukelich, C., \& Risko, V. (2001). Reflection and learning to teach reading: A critical review of literacy and general teacher education studies. Journal of Literacy Research, 33(4), 595-635.

18. Ruan, J., \& Beach, S.A. (2005). Using online peer dialogue journaling to promote reflection in elementary pre-service teachers. Action in Education, 27(3), 64-75.

19. Schon, D.A. (1983). The reflective practitioner: How professionals think in action. New York: Basic Books, Inc.

20. Schon, D.A. (1996). Educating the reflective practitioner: Toward a new design for teaching and learning in the professions. San Francisco: Jossey-Bass, Inc.

21. Strauss, A.L., \& Corbin, J. (1998). Basics of qualitative research. Thousand Oaks, CA: Sage Publications.

22. Urzua, A., \& Vasquez, C. (2008). Reflection and professional identity in teachers' future-oriented discourse. Teaching and Teacher Education: An International Journal of Research and Studies, 24(7), 1935-1946.

23. Vygotsky, L.S. (1978). Mind in society. Cambridge, MA: Harvard University.

24. Wenger, E.C., \& Snyder, W.M. (2000). Communities of practice: The organizational frontier. Harvard Business Review, 78(1), 139-145.

25. Windschitl, M. (1998). The WWW and classroom research: What path should we take? Educational Researcher, 27, 28-33.

26. Wood, A.F., \& Smith, M.J. (2005). Online communication: Linking technology, identity, and culture (2nd ed.). Mahwah, NJ: Lawrence Erlbaum Associates, Inc., Publishers.

27. Zeichner, K.M., \& Liston, D.P. (1996). Reflective teaching: An introduction. Mahwah, NJ: Lawrence Erlbaum Associates, Inc., Publishers. 